\title{
Localization of Iron in Grains of Arobic Rice (Oryza sativa L.) by Histochemical Method
}

\author{
D.B. Santhosh*, A.N. Ramesh, G.M. Santhosh, H.E. Shashidhar and D. Dayal Doss \\ Department of Plant Biotechnology, University of Agricultural Sciences, \\ GKVK, Bengaluru-65, India \\ *Corresponding author
}

\section{A B S T R A C T}

Keywords

Iron,

Grains,

Arobic rice,

Histochemical

method

Article Info

Accepted:

08 July 2018

Available Online:

10 August 2018
Micronutrient malnutrition has reached to alarming situation with billions of people suffering from Iron, Zinc and Vitamin-A deficiencies. Micronutrient supplementation, food fortification, and biofortification are the three basic approaches used to alleviate micronutrient deficiencies. In the present study ten genotypes rich in iron were used. The crop was grown under aerobic condition and harvested rice grains used for the study. Localization of iron in rice grain was done using Perl's Prussian blue staining of aerobic rice grain sections showed distribution of iron accumulation (blue compound of ferric ferrocyanide) throughout the alureone and subaleurone layers.

\section{Introduction}

Aerobic rice is responsive to high inputs (water, nutrients) to reach high yields under non-flooded conditions. In China, the Upland Rice Laboratory of the Chinese Agriculture University (CAU) is breeding the aerobic rice varieties, called "Han Dao" by Bouman et al., (2002) (1). In India, University of Agricultural Sciences (UAS), GKVK, Bengaluru developed aerobic rice variety called "BI-33" released in 2009 (Gowda et al., (2011) (2); www.aerobicrice.in), MAS 956-1 and MAS 26 released in 2008 (www.aerobicrice.org).
Histochemistry is a powerful technique for localization of trace quantities of substances present in biological tissues. Histochemical techniques have been employed to characterize structure and development, and to study time course of deposition and distribution of major storage compounds such as protein, lipid, starch, phytin, and minerals such as calcium, potassium and iron in rice grains (Krishnan et al., (2001) (3); Krishnan and Dayanandan (2003) (4)). Iron is found in haemoglobin, which transports oxygen in the blood of vertebrates. When iron levels are low, the amount of available oxygen declines, 
causing a common symptom of iron deficiency called anaemia. Iron deficiency causes a range of health problems in humans, including poor pregnancy-related complications, brain damage in infants, chronic hypoxia and reduced work performance by Goto and Yoshihara (2001) (5). Dietary iron deficiency owing to an insufficient and inappropriate diet is a severe nutritional problem by Goto et al., (2001) (6) that affect $30 \%$ of the world's population by WHO (1992) (7).

Plant-based foods are potential sources of all essential minerals and organic nutrients that are directly or indirectly required by humans. Rice is the most important staple food crop in the world; nearly half of the world's population depends on rice as the source of their calories. Hence make an effort to know the distribution of iron within the rice grains.

\section{Materials and Methods}

Perl's Prussian blue technique was employed for localization of iron by Pearse, (1972) (8). This is an extremely reliable and sensitive technique that can even detect small quantities of iron microscopically. Rice caryopses were soaked in distilled water for about 2-3 hours.
Thin transverse sections of aerobic rice grains were treated with a mixture of freshly prepared $2 \%$ potassium ferrocyanide and $2 \%$ hydrochloric acid for 20-30 min. Prussian blue stain. The treatment with acid was done to release ferric ions from the tissue, which immediately reacts with the cation of potassium ferrocyanide to produce a blue insoluble compound, ferric ferrocyanide. Observations and photographs were taken using a microscope Krishnan et al., (2003) (9).

\section{Results and Discussion}

In the present study, ten elite lines of aerobic brown rice grain of transverse sections showed bright blue color indicates the presence of iron in the sections of aerobic rice grains are presented in the figures 1-10. The highest bright blue color was observed in Jeerigesanna fallowed by Jaya, BJ-21, AM-1, AM-72, Chittimuthyalu, AM-65, ARB-6, Black rice and Azucena. It clearly indicates that distribution of iron and accumulation (blue compound of ferric ferrocyanide) was high in the alureone and sub-aleurone layers. Similar results reported by Pearse (1972) (8), 1988(10); Krishnamurthy, (1998) (11).

\section{Localization of iron in aerobic rice grains}

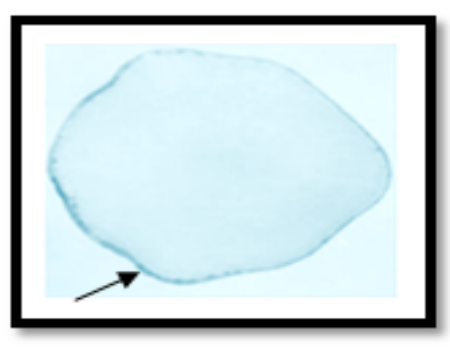

Fig 1: AM-72

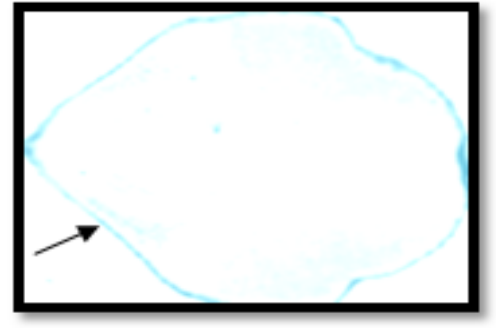

Fig 2: ARB-6 


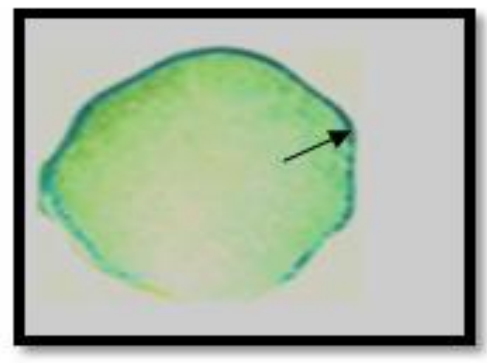

Fig 3: Jeerigesanna

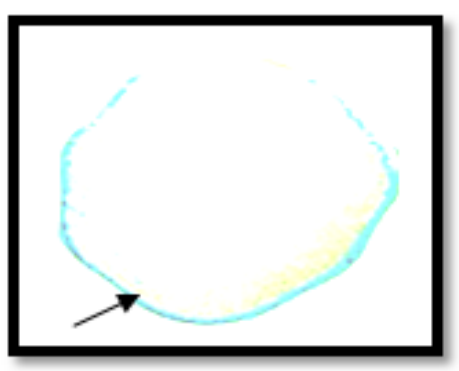

Fig 5: BJ-21

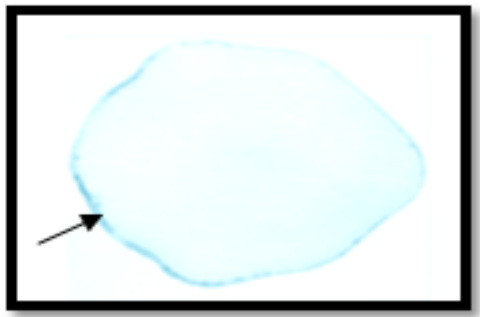

Fig 7: AM-65

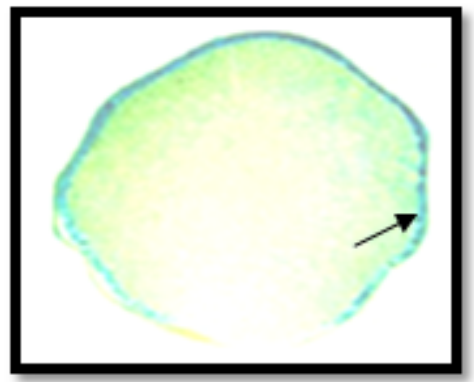

Fig 9: Jaya

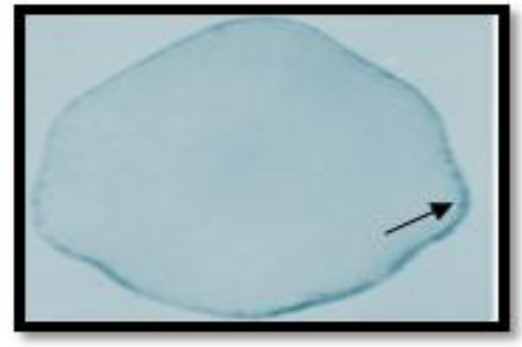

Fig 4: AM-1

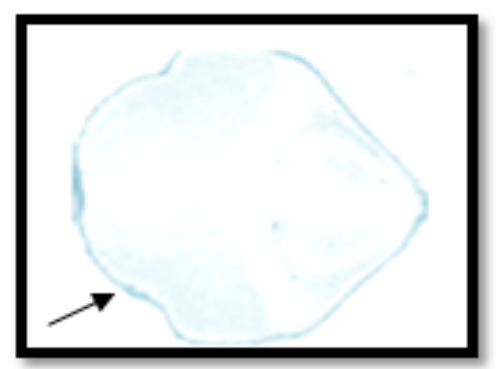

Fig 6: Black rice

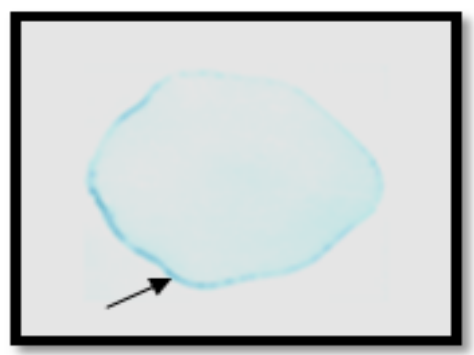

Fig 8: Chittimuthyalu

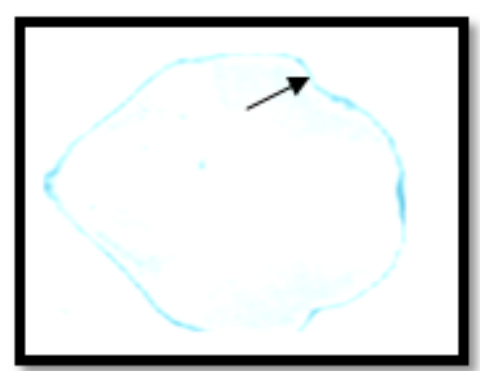

Fig 10: Azucena
It was shown that histochemical analysis is a powerful tool and can be used for preliminary screening of biofortified aerobic rice lines with high iron content (qualitatively) to select the desired line for further analysis. This technique does not require antibody or radiolabelled probe. Previously, iron content of grains was measured only by chemical 
analysis. But this method is beset by technical problems when dealing with a large germplasm screening and limited amounts of sample materials. It has also been reported that iron content could vary widely among rice genotypes by Prom-u-thai et al., (2003) (12). The histochemical technique can easily be used in large germplasm screenings to select the right background material for genetic engineering or for breeding programmes.

\section{References}

Bouman B. A. M., Xiaoguang Y., Huaqi W., Zhiming W., Junfang Z., Changgui W. and Bin, C. 2002. a new way of growing rice in water-short areas. In Proceedings of the $12^{\text {th }}$ International Soil Conservation Organization Conference, 26-31 May, Beijing, China. Tsinghna University Press., 175-181.

Gowda V. R. P., Henry A., Yamauchi, A. Shashidhar H. E. and Serraj R. 2011. Root biology and genetic improvement for drought avoidance in rice. Field Crop. Res., 122, 1-13.

Krishnan S., Ebenezer G. A. I. and Dayanandan P. 2001. Histochemical localization of storage components in caryopsis of rice (Oryza sativa L.).
Curr. Sci., 80, 567-571.

Structural and histochemical studies on grainfilling in the caryopsis of rice (Oryza sativa L). J. Biosci. Bioeng., 28, 455469.

Goto, F. and Yoshihara, T. 2001. Iron fortification of rice seed by the soybean ferritin gene. National Biotech., 17, 282-286.

Goto, F., Yoshihara, T. and Saiki, H. 2001. Iron accumulation in tobacco plants expressing soyabean ferritin gene. Trans. Res., 7, 173-180.

WHO., 1992; Geneva.

Pearse A. G. E., 1972. Histochemistry: theoretical and applied, Vol. II, 3rd edition. Churchill Livingstone, Edinburgh.

Krishnan S., Datta K., Baisakh N., De vasconcelos M. and Datta S. K. 2003. Tissue-specific localization of $\beta$ carotene and iron in transgenic indica rice (Oryza sativa L.). Curr. Sci., 84, 1232-1234.

Pearse, A. G. E. 1988. Histochemistry: theoretical and applied, Vol I, 4th edition. Longman, London.

Krishnamurthy K. V. 1998. Methods in plant histochemistry, Chennai.

Prom-u-thai, C. and Rerkasen, B. 2003. Easy and rapid detection of iron in rice grain. Sci. Asia., 29, 203-207.

\section{How to cite this article:}

Santhosh, D.B., Ramesh, A.N., Santhosh, G.M., Shashidhar, H.E. and Dayal Doss, D. 2018. Localization of Iron in Grains of Arobic Rice (Oryza sativa L.) by Histochemical Method. Int.J.Curr.Microbiol.App.Sci. 7(08): 1048-1051. doi: https://doi.org/10.20546/ijcmas.2018.708.118 